\title{
Compound heterozygous c.598_612del and c.1746-20C > G CAPN3 genotype cause autosomal recessive limb-girdle muscular dystrophy-1: a case report
}

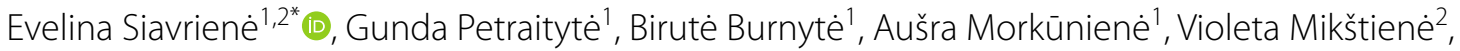
Tautvydas Rančelis ${ }^{1,2}$, Algirdas Utkus ${ }^{1,2}$, Vaidutis Kučinskas ${ }^{1}$ and Eglè Preikšaitiené ${ }^{1}$

\begin{abstract}
Background: Autosomal recessive limb-girdle muscular dystrophy-1 (LGMDR1), also known as calpainopathy, is a genetically heterogeneous disorder characterised by progression of muscle weakness. Homozygous or compound heterozygous variants in the CAPN3 gene are known genetic causes of this condition. The aim of this study was to confirm the molecular consequences of the CAPN3 variant NG_008660.1(NM_000070.3):C.1746-20C > G of an individual with suspected LGMDR1 by extensive complementary DNA (CDNA) analysis.
\end{abstract}

Case presentation: In the present study, we report on a male with proximal muscular weakness in his lower limbs. Compound heterozygous NM_000070.3:c.598_612del and NG_008660.1(NM_000070.3):c.1746-20C > G genotype was detected on the CAPN3 gene by targeted next-generation sequencing (NGS). To confirm the pathogenicity of the variant c. 1746-20C > G, we conducted genetic analysis based on Sanger sequencing of the proband's cDNA sample. The results revealed that this splicing variant disrupts the original $3^{\prime}$ splice site on intron 13 , thus leading to the skipping of the DNA fragment involving exon 14 and possibly exon 15. However, the lack of exon 15 in the CAPN3 isoforms present in a blood sample was explained by cell-specific alternative splicing rather than an aberrant splicing mechanism. In silico the c.1746-20C > G splicing variant consequently resulted in frameshift and formation of a premature termination codon (NP_000061.1:p.(Glu582Aspfs*62)).

Conclusions: Based on the results of our study and the literature we reviewed, both c.598_612del and c.1746$20 C>G$ variants are pathogenic and together cause LGMDR1. Therefore, extensive mRNA and/or cDNA analysis of splicing variants is critical to understand the pathogenesis of the disease.

Keywords: CAPN3, LGMDR1, CDNA assay, Splicing variant, Compound heterozygosity

*Correspondence: evelina.siavriene@mf.vu.It

${ }^{1}$ Department of Human and Medical Genetics, Institute of Biomedical

Sciences, Faculty of Medicine, Vilnius University, Santariskiu street 2, LT-08661 Vilnius, Lithuania

Full list of author information is available at the end of the article

\section{Background}

Limb-girdle muscular dystrophies (LGMD) are a group of genetically heterogeneous disorders characterised by a wide spectrum of clinical features and different rates of progression. More than 30 different genetic subtypes of LGMD have been identified. Autosomal recessive limbgirdle muscular dystrophy-1 (LGMDR1; MIM \#253600; ORPHA \#267), which was formerly referred to as original author(s) and the source, provide a link to the Creative Commons licence, and indicate if changes were made. The images or other third party material in this article are included in the article's Creative Commons licence, unless indicated otherwise in a credit line to the material. If material is not included in the article's Creative Commons licence and your intended use is not permitted by statutory regulation or exceeds the permitted use, you will need to obtain permission directly from the copyright holder. To view a copy of this licence, visit http://creativecommons.org/licenses/by/4.0/. The Creative Commons Public Domain Dedication waiver (http://creativecommons.org/publicdomain/zero/1.0/) applies to the data made available in this article, unless otherwise stated in a credit line to the data. 
LGMD2A, is the most prevalent form of LGMD in many countries $[1,2]$.

Although the underlying pathological mechanisms involved in LGMDR1 are not well known, studies of Capn3 knockdown mice identified a human calpainopathy-like phenotype, thus indicating that this disease is caused by defects in the CAPN3 gene (MIM \#114240), which is located on chromosome 15q15 [3]. A number of different studies have demonstrated that the homozygous or compound heterozygous genotype of CAPN3 lead to the pathogenesis of LGMDR1. Meanwhile, the heterozygous CAPN3 variants have been reported to cause autosomal dominant limb-girdle muscular dystrophy-4 (LGMDD4; MIM \#618129; ORPHA \# 102014), which has a later onset and milder phenotype than LGMDR1 $[2,4$, 5]. Besides DNA sequence variants in the CAPN3 gene, it has been suggested that other genetic and environmental factors modulate the clinical phenotype of LGMDR1, because variable degrees of muscle involvement and disease progression have been reported in individuals with the same genetic variant [6].

The Human Gene Mutation Database (HGMD) and Leiden Open Variation Database (LOVD) report more than 400 pathogenic DNA sequence variants of the CAPN3 gene, the majority of which are missense or nonsense variants $[7,8]$. The splicing variants accounting for about $15 \%$ of total variants are also a common cause of LGMDR1. Since the consequences of splicing variants on mRNA transcripts have been mostly inferred by in silico analysis, it is conceivable that the frequency of these disease-causing variants could be higher after experimental complementary DNA (cDNA) analysis. In order to accurately assess the pathogenicity of splicing variants at the mRNA level, detailed molecular and/or functional analysis is required [6, 9]. Therefore, this research strategy has been used in this study to confirm the molecular consequences of the variant NG_008660.1(NM_000070.3):c.1746-20C > G of the CAPN3 gene of an individual with LGMDR1.

\section{Case presentation}

The proband, a 43-year-old Lithuanian man, with proximal muscular weakness in his lower limbs, presented initially at age 17 with walking difficulties. Five years later he developed weakness in his shoulder girdle. A neurological examination at the age of 37 revealed atrophy of his shoulder girdle, wasting of biceps and triceps, thinning of thighs, pseudo hypertrophy of both calves, and winged scapulae. Gower's sign was positive. Muscle strength was $4 / 5$ (MRC-scale) at both shoulders, $4 / 5$ at both elbows, $4 / 5$ at both wrists, $3 / 5$ at both hip joints, $3 / 5$ at both knees, and 2/5 at both ankles. His facial muscles were not involved. His creatine kinase (CK) level was 3451 U/L (ref. range $<195 \mathrm{U} / \mathrm{L}$ ). Needle electromyography showed chronic myopathic changes. The proband did not have any cardiac or pulmonary involvement. Family history was unremarkable. The clinical phenotype, age of presentation, and course of the disease were consistent with a diagnosis of LGMDR1 [10].

With a clinical suspicion of muscular dystrophy or myopathy, targeted amplicon sequencing was performed using next-generation sequencing (NGS). Genomic DNA (gDNA) was extracted from peripheral venous blood samples of our proband and his family members following the phenol-chloroform-isoamyl alcohol protocol [11]. Targeted amplicon sequencing was done for this individual using the gene panel for neuromuscular disorders on an Ion Torrent (Ion Personal Genome Machine; Thermo Fisher Scientific, USA). Multiplex primer pools were designed using Ion AmpliSeq Designer software (Thermo Fisher Scientific, USA). This custom gene panel consisted of 297 genes (Table S2) and covered $99.96 \%$ of the exonic region, including the flanking exon-intron boundary regions. Enrichment of exonic sequences was performed with an Ion AmpliSeq Library Kit 2.0 (Thermo Fisher Scientific, USA) and sequenced on an Ion PGM (Thermo Fisher Scientific, USA) using 318 Chip (Thermo Fisher Scientific, USA) according to the manufacturer's protocol. Data analysis was performed using Ion Torrent software (Thermo Fisher Scientific, USA). After the analysis pipeline was processed, 1194 genome variants were identified from obtained sequence data. ANNOVAR [12] was used to annotate and prioritize DNA sequence variants of the CAPN3 gene. After filtering methods were applied, only one non-frameshift deletion (rs727503837) of the CAPN3 gene has matched with proband's phenotype. This deletion has been previously confirmed as pathogenic in a few individuals with LGMDR1 (PMID \#9452114 [13], \#25135358 [14], \#18854869 [15], \#16141003 [16]) as well as ClinVar [17] database. Therefore, this deletion was the main candidate for the proband's phenotype. Based on the clinical phenotype, age of presentation, and course of the disease, the autosomal recessive (R1) subtype of the LGMD has been suspected. For this reason, the hypothesis of compound heterozygosity has been raised. The intronic variant (rs201892814) in the CAPN3 gene, which has low frequency in population and has damaging value by RegSNPs-intron tool [18], was selected as another possible candidate. The classification of these genetic variants for the proband's phenotype was assessed using criteria outlined by the American College of Medical Genetics (ACMG) [19]. The c.598_612del variant was classified as "pathogenic", according to such criteria as PS4, PM1, PM2, PM4, PP1, PP3. Based on the PS3, PM2, PM4, PP3 
criteria, the second c.1746-20C > G variant was classified as "likely pathogenic".

Confirmation of CAPN3 variants identified by NGS and familial segregation analysis were performed through Sanger sequencing using BigDye Terminator v.3.1Cycle Sequencing Kit and ABI3130xl automated sequencer (Life Technologies, USA). Polymerase chain reaction (PCR) of CAPN3 exon 4 and exon 14 as well as further Sanger sequencing was performed according to the manufacturer's protocol on proband's and his parents' samples. The relative exons and flanking intron regions were amplified using primers (Table S1) designed by Primer3 [20]. Sanger sequencing results were analysed with Sequence Analysis v.5.1 (Thermo Fisher Scientific, USA) and Chromas v.2.4.4 (Technelysium Pty Ltd., Australia) software. The resulting sequence was aligned with the reference sequence of the CAPN3 gene (NCBI: NG_008660.1).

To confirm the pathogenicity of the detected splice site variant, genetic analysis of proband's cDNA sample was performed. Total RNA of the proband was extracted from the whole blood using Tempus ${ }^{\mathrm{TM}}$ Blood RNA Tube and Tempus ${ }^{\mathrm{TM}}$ Spin RNA Isolation Kit (Thermo Fisher Scientific, USA) according to the optimized manufacturers' protocols. Complementary DNA (cDNA) was synthesized from total RNA using a High Capacity RNAto-cDNA Kit (Thermo Fisher Scientific, USA) following manufacturer's protocol. PCR of cDNA sequence flanking CAPN3 splicing variant was performed using specific primers (Table S1) designed with Primer Blast [21]. Proband's PCR products were sequenced via Sanger sequencing technique and aligned with the reference sequence of the CAPN3 gene (NCBI: NM_000070.3) as indicated above.

The pathogenicity of identified DNA sequence variants was evaluated by a review of scientific literature and analysis of databases, such as HGMD [7], LOVD [8], 1000 genomes [22], dbSNP [23], ClinVar [17], OMIM [24], Orphanet [25], Ensembl [26], and gnomAD browser [27]. MutationTaster 2 [28], Human Splicing Finder [29], and regSNPs splicing [30] tools were used for predicting splice site alterations. Sequences of evolutionary distinct species were obtained from the Ensembl genome browser [26], while a sequence alignment was produced using ClustalO tool [31]. Possible splice site variant's effect on the CAPN3 protein (UniProtKB: P20807) was predicted using different tools and databases, e.g., UniProt [32], ExPASy Bioinformatics Resource Portal [32], and Pfam 32.0 database [33].

After targeted NGS and in silico analysis, compound heterozygous NM_000070.3:c.598_612del and NG_008660.1(NM_000070.3):c.1746-20C > G CAPN3 genotype were detected. Sanger sequencing confirmed the segregation of these variants in the family: the father was determined to be a heterozygous carrier of the c.598_612del variant, while the mother was heterozygous for the c.1746-20C > G variant (Fig. 1A). In silico analysis revealed that the c.598_612del variant has been reported as an intragenic deletion (rs727503837) that leads to the loss of five amino acids (NP_000061.1:p.(Phe200_Leu204del)) at the protein level (Fig. 1C). Even though the second variant, c.1746-20C > G (rs201892814), with the minor allele frequency (MAF) lower than 0.01 , is also rare, the interpretation of its pathogenicity based on ClinVar [17] and LOVD data [8] is still uncertain. A variant effect prediction method, MutationTaster 2 [28], predicted the variant to be benign. However, Human Splicing Finder [29] and regSNPs [30] predicted that this DNA sequence variant would most probably affect splicing of precursor messenger RNA (pre-mRNA) by activation of an intronic cryptic acceptor site. Sequence alignment of the CAPN3 protein across six evolutionarily distant species revealed that the region flanking the splicing variant is highly conserved (Fig. 1D). Sanger sequencing results showed two different transcripts corresponding to the isoform without exon 15 and the isoform without both exon 14 and exon 15 (Fig. 1B). Further computational analysis demonstrated that the isoform without exon 15 leads to the loss of six amino acids (NP_000061.1:p. (Lys595_Lys600del)), while the isoform without both exon 14 and 15 results in a translational frameshift of 62 amino acids and formation of a premature termination codon (NP_000061.1:p.(Glu582Aspfs"62)) (Fig. 1C).

\section{Discussion}

DNA sequence variants altering pre-mRNA splicing account for at least $15 \%$ of disease-causing variants [34]. These variants affect pre-mRNA processing through exon skipping, intron inclusion, cryptic splicing, leaky splicing, or even introduction of pseudo-exons into the processed mRNA. Since these genetic variants have different consequences, they are especially difficult to predict by in silico analysis. In order to accurately assess the effects of splicing variants at the mRNA level, experimental mRNA or cDNA analysis is necessary $[9,35,36]$.

In this study, we present a characterisation of the CAPN3 splicing variant (NG_008660.1(NM_000070.3):c.1746-20C>G), for which there is conflicting data. This variant was earlier identified in several unrelated individuals with LGMDR1 [2, 37-39]. However, the consequences of c.1746-20C > G are mostly unsupported by experimental data; only a few studies have reported results based on cDNA and/or protein analysis. After performing cDNA and Western blot analysis, Krahn et al. (2007) reported no changes in CAPN3 mRNA transcripts but did find reduced protein 

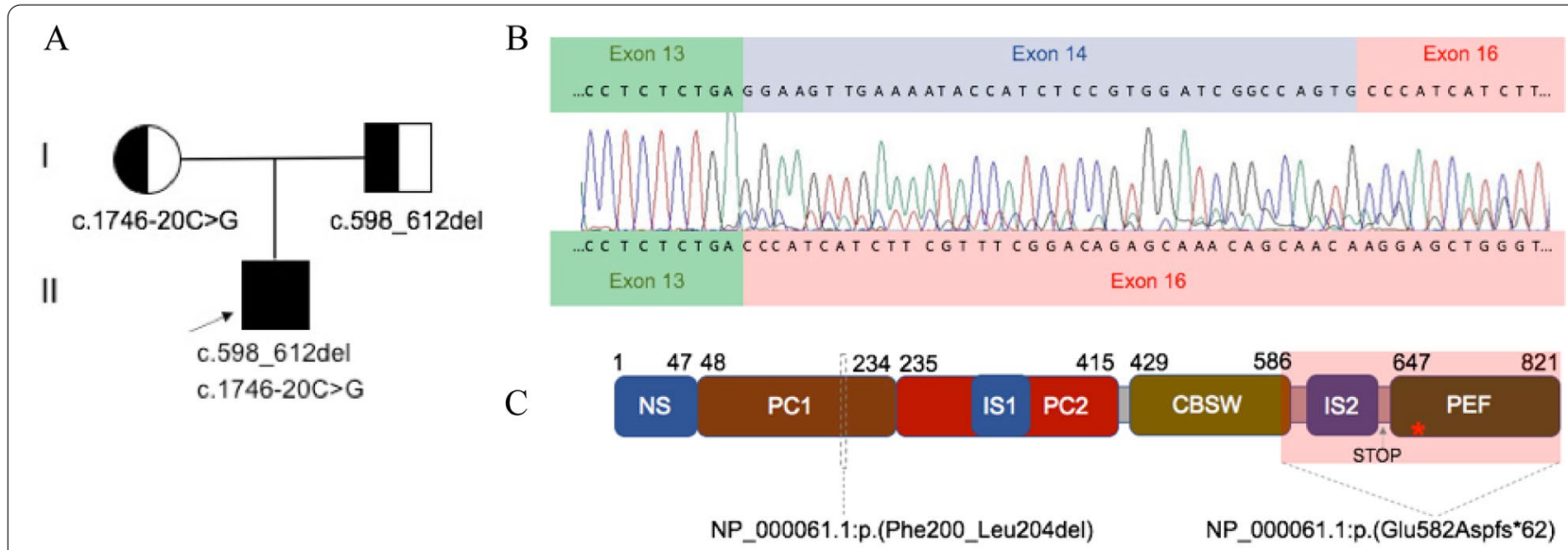

D

Proband (E14 and E15 skipped)
Proband (E15 skipped)
Homo sapiens
Mus musculus
Rattus norvegicus
Monodelphis domestica
Gallus gallus
Sus scrofa

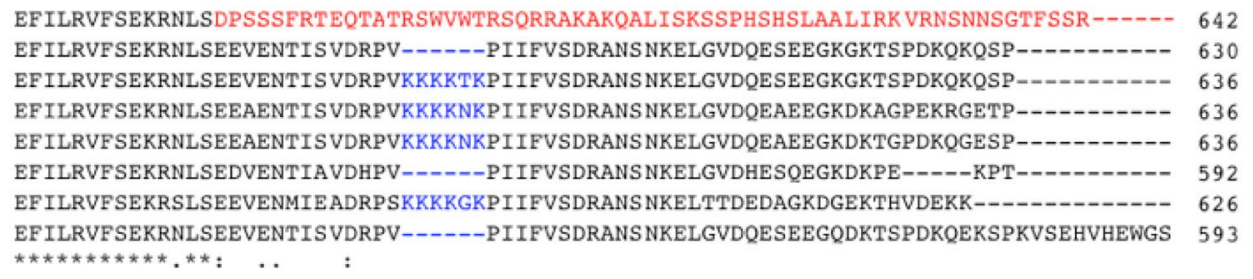

Fig. 1 A Segregation of compound heterozygous variants C.598_612del and c.1746-20C > G of CAPN3 in the family; B Representative Sanger sequencing electropherogram of the proband's cDNA sample showed two different transcripts corresponding to the isoform lacking exon 15 and the isoform lacking both exon 14 and exon 15; C A schematic representation of the CAPN3 protein, which is 821 amino acids in length, with the approximate position of the premature termination (STOP) codon in relation to the last exon-exon junction $\left(^{*}\right)$ and the arrangement of the main domains: N-terminal addition sequence (NS), two protease core domains (PC1 and PC2), insertion sequence 1 (IS1), calpain-type $\beta$-sandwich domain (CBSW), insertion sequence 2 (IS2), and penta E-F hand domain (PEF) [50]; D A comparative sequence alignment produced by ClustalO of the CAPN3 protein across six evolutionarily distant species. Frameshift of 62 new amino acids and therefore a truncated sequence due to lack of both exon 14 (E14) and exon 15 (E15) is highlighted in red. Blood-specific alternative splicing of exon 15 (E15), which encodes six amino acids, is highlighted in blue

expression [38]. In a similar study, Nascimbeni et al. (2010) reported that the c.1746-20C > G variant altered both mRNA splicing and protein expression [2]. In independent parallel study Macias et al. (2021) researched the CAPN3 variants in non-coding regions or potential regulatory sequences in individuals with the LGMDR1 phenotype. The compound heterozygous c.598_612del and c.1746-20C > G CAPN3 genotype was also detected in four unrelated individuals. Similarly to our proband, they all presented uniformly with mature adult disease onset and no contractures. However, in our proband lower-limb weakness was predominant, while two individuals presented by Macias et al. (2021) had prevailing upper-limb weakness. Even though the reduction of the CAPN3 protein amount in most Western blot samples was detected, analysis of mRNA transcripts was not performed in this parallel study [40]. Therefore, the molecular consequences of the c.1746-20C > G splicing variant at cDNA level are still unknown.

Deep intronic variants, including c.1746-20C > G, which is located twenty nucleotides upstream of the $3^{\prime}$ acceptor site, usually create new splice sites resulting in the inclusion of cryptic exons. In the study done by Nascimbeni et al. (2010), the c.1746-20C > G splicing variant resulted in the exonisation of all or part of intron 13 in six unrelated individuals with LGMDR1. However, Sanger sequencing of the proband's cDNA sample in the present study revealed that this variant disrupts the original $3^{\prime}$ splice site in intron 13 , thus leading to skipping of exon 14 and possibly exon 15 . Two different transcripts corresponding to the isoform lacking exon 15 and the isoform lacking both exon 14 and exon 15 have been identified with possibly lower quantity of the latter in the cDNA sample (Fig. 1B). The presence of different mRNA transcripts in the blood sample of our proband could be explained as different consequences of a mutant splicing mechanism or blood-specific alternative splicing. As demonstrated in the study performed by Nascimbeni et al. (2010), the same pathogenic splicing variant can result in two or more aberrant transcripts in a certain tissue 
[2]. On the other hand, pre-mRNA splicing is a normal cellular process contributing to the production of functional protein and ensuring protein diversity in the cell. For instance, the study of the NF1-coding region of two non-affected individuals showed 46 different transcripts of this gene $[9,41]$. Also, different transcripts can be expressed in diverse tissues or cell types, thus ensuring specific biological functions [42]. In an investigation of 26 individuals with LGMDR1, Blázquez et al. (2008) identified four different CAPN3 mRNA transcripts in white blood cells (WBCs): an isoform lacking exon 15, an isoform lacking exons 15 and 16, an isoform lacking exons 6 and 15, and an isoform without these three exons. Moreover, the comparative analysis of peripheral blood and muscle samples showed that the c. $1782+1072 \mathrm{G}>\mathrm{C}$ splicing variant results in the insertion of $100 \mathrm{bp}$ of intron 14 between exons 14 and 16 in WBCs and between exons 14 and 15 in the muscle sample [5]. Based on these findings, the absence of exon 15 in all the isoforms in individuals' peripheral blood samples could be explained by the alternative splicing isoform rather than the mutant isoform. Therefore, the c.1746-20C $>$ G splicing variant in the proband's cDNA sample is most likely to result in the loss of only exon
14, while the loss of exon 15 is supposed to be caused by the blood-specific alternative splicing (Fig. 2B).

In silico, the CAPN3 c.1746-20C > G splicing variant causes a translational frameshift and formation of a premature termination codon, thus resulting either in protein truncation or mRNA degradation due to nonsense-mediated decay (NMD). During this cellular process, the degradation of mRNAs that harbour a premature termination codon at least 200 nucleotides downstream of the start codon and 50-55 nucleotides upstream of the last exon-exon junction can be induced [43-45]. The premature termination codon induced by the c.1746-20C $>\mathrm{G}$ splicing variant of the CAPN3 gene conforms to the conditions for NMD (Fig. 1C), and therefore the mRNA degradation process could be initiated. However, the presence of both wild type and altered transcript in our study indicates that these transcripts do not undergo full NMD but may also result in the production of the truncated protein. To confirm this assumption, more detailed analysis (e.g., Western blot) at the protein level could be suggested. Nevertheless, both partial reduction of mRNA transcripts and truncated protein due to the CAPN3 splicing variant would be deleterious and contribute to LGMDR1 pathogenesis.

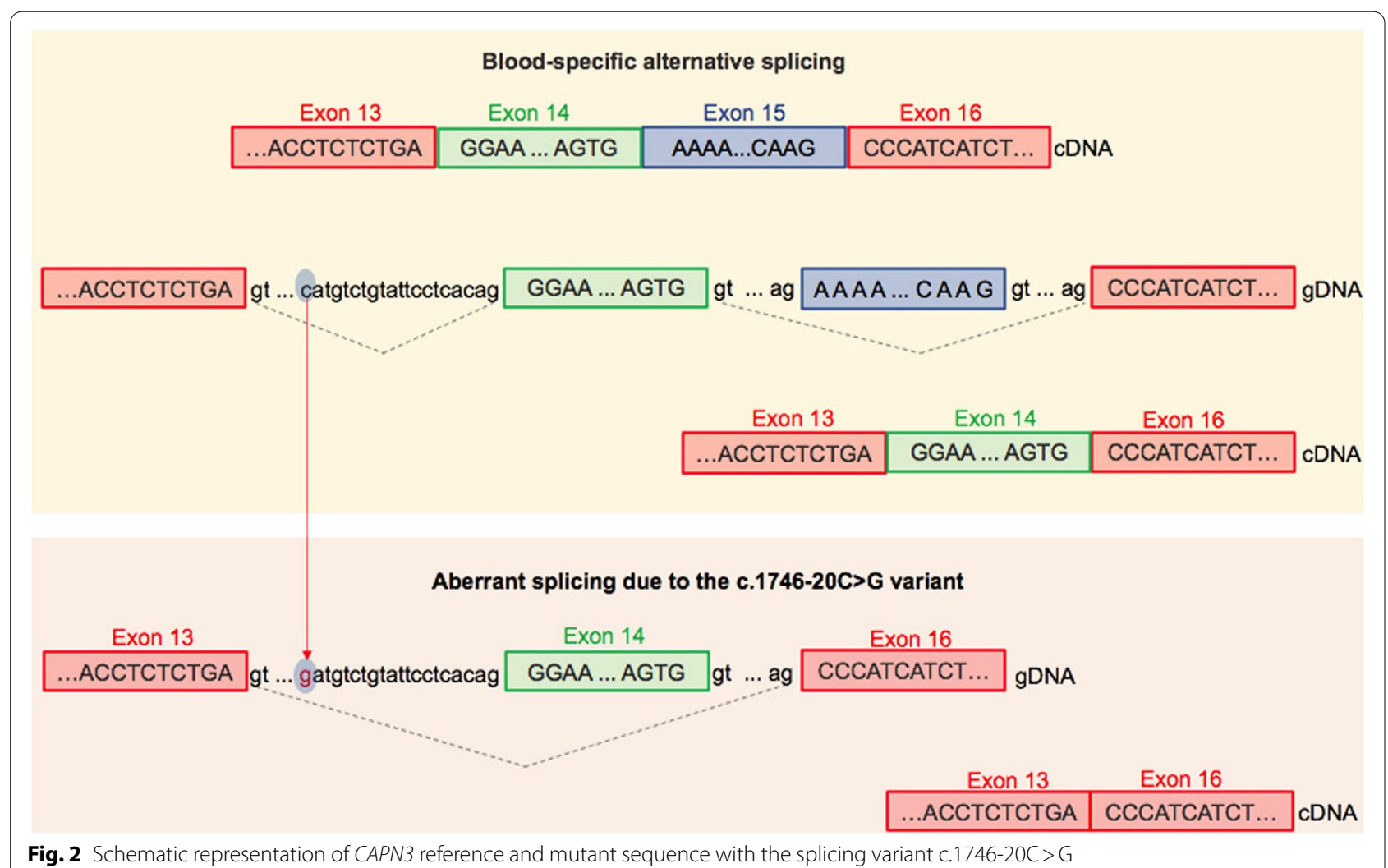

Fig. 2 Schematic representation of CAPN3 reference and mutant sequence with the splicing variant c.1746-20C > G 
LGMDR1 was the first human disease found to be caused by alterations of the enzyme calpain. Calpain-3 (UniProtKB \#P20807), which is encoded by the CAPN3 gene, belongs to the calpain superfamily of $\mathrm{Ca}^{2+}$-regulated non-lysosomal cysteine proteases and are found in almost all eukaryotes [3]. According to the GTEx Portal [46], CAPN3 is expressed in almost all human tissues. The product of CAPN3 therefore has essential functions in many cellular processes, including cell differentiation and motility, apoptosis, and regulation of the cell cycle and signal transduction system. The conventional calpains (CAPN1, CAPN2, and CAPN3) are structurally similar and share four domains: two protease core domains (PC1 and PC2), a calpain-type $\beta$-sandwich domain (CBSW), and a penta E-F hand domain (PEF), which are critical for $\mathrm{Ca}^{2+}$-dependent protein activation. Differently from other calpain family members, CAPN3 also has three unique regions: $\mathrm{N}$-terminal addition sequence (NS), insertion sequence 1 (IS1), and insertion sequence 2 (IS2) (Fig. 1C). Due to these unique regions, CAPN3 has additional properties: $\mathrm{Na}^{+}$-dependent protein activation and extremely fast autodegradation. Moreover, previous studies have shown that the N2A region of titin, which is encoded by TTN (MIM \#188840), binds to the IS2 region and stabilises CAPN3 by preventing its autodegradation. The IS2 region, which is partly encoded by exon 15 of $C A P N 3$, therefore plays an important role in regulation of gene expression [47-49]. Based on GTEx data [46], the highest expression of both CAPN3 and TTN is reported in skeletal muscles, while expression of these genes in whole blood samples is minimal. Since their functions are considered non-essential in whole blood samples and there is no need to stabilise the CAPN3 protein, the CAPN3 mRNA transcript without exon 15 could be explained by cell-specific alternative splicing occurred during evolutionary processes. Furthermore, the sequence alignment of the CAPN3 protein across six evolutionarily distant species revealed that exon 15 , encoding only six amino acids, is also alternatively spliced in the cDNA sequence of opossums (Monodelphis Domestica) and pigs (Suc Scrofa). Contrarily, the region spanning the splicing variant c.1746-20C $>$ G is highly conserved in all organisms that have been analysed, thus suggesting that this region is fundamentally important (Fig. 1D).

The compound heterozygous c.598_612del and c.174620C>G CAPN3 genotype was predicted by computational analysis to affect the proband's functional protein domains. At the protein level, the c.598_612del variant detected in exon 4 was predicted to result in a loss of five amino acids (NP_000061.1:p.(Phe200_Leu204del) in the $\mathrm{PC} 1$ domain. Meanwhile, a variant disrupting the original $3^{\prime}$ splice site in intron 13 was predicted to result in either partial degradation of mRNA transcripts or a translational frameshift and formation of premature termination codon. In the case of a protein truncation (NP_000061.1:p.(Glu582Aspfs"62), CAPN3 lacks IS2, PEF, and part of the CBSW domain due to the c.1746$20 \mathrm{C}>\mathrm{G}$ splicing variant (Fig. 1C). Based on the results of our study and the literature we reviewed, both DNA sequence variants are pathogenic and cause LGMDR1.

\section{Limitations}

The predicted lower expression of the CAPN3 protein has not been confirmed by Western blotting, because of the unavailability of proband's cell culture.

\section{Conclusions}

In this study we report a compound heterozygous c.598_612del and c.1746-20C > G CAPN3 genotype leading to LGMDR1. Moreover, by confirming the consequences of the splicing variant c.1746-20C $>$ G at the mRNA level, we provide additional evidence that extensive mRNA and/or cDNA analysis is highly informative for the evaluation of these DNA sequence variants and the relationship between genotype and phenotype. This research strategy could be suggested in the routine practice of medical genetics.

\section{Supplementary Information}

The online version contains supplementary material available at https://doi. org/10.1186/s12891-021-04920-3.

Additional file 1 : Supplementary Table 1. The conditions for PCR amplification of the CAPN3 gene in gDNA and CDNA samples.

Additional file $\mathbf{2}$ : Supplementary Table 2 . The list of genes that are included in the Ion AmpliSeq ${ }^{\mathrm{TM}}$ On-Demand panel for targeted sequencing.

\section{Acknowledgements}

We are grateful for the family for participating in our study.

\section{Authors' contributions}

All authors contributed to the study conception and design. ES wrote the manuscript; ES and GP carried out the genetic experiments and analysed obtained results with the support from VM; BB provided a genetic counselling to the proband; AM performed the NGS experiment; ES and TR performed bioinformatic analysis; $A U$ and VK supervised the findings of this work; EP conceived the original idea of this study. All authors have read and approved the manuscript.

\section{Funding}

This study was funded by a grant (No. S-MIP-20-34; ANELGEMIA project) from the Research Council of Lithuania. The funder had no role in study design, data collection and analysis, decision to publish, or preparation of the manuscript.

\section{Availability of data and materials}

The main data generated and analysed during this study are included in this article and its supplementary information file. Any additional information is available from the authors upon request. 


\section{Declarations}

\section{Ethics approval and consent to participate}

The blood has been collected from the proband and his parents, after obtaining written informed consent at the Centre for Medical Genetics, Vilnius University Hospital Santaros Klinikos. The study was approved by the Vilnius Regional Biomedical Research Ethics Committee of Lithuania. The proband provided the written consent for the research study.

\section{Consent for publication}

This manuscript has the consent of the proband and his parents for the use of their data. The family provided the written consent for the case report to be published.

\section{Competing interests}

The authors declare that they have no competing interests.

\section{Author details}

${ }^{1}$ Department of Human and Medical Genetics, Institute of Biomedical Sciences, Faculty of Medicine, Vilnius University, Santariskiu street 2, LT-08661 Vilnius, Lithuania. ${ }^{2}$ Biobank of Lithuanian Population and Rare Disorders, Institute of Biomedical Sciences, Faculty of Medicine, Vilnius University, Vilnius, Lithuania.

Received: 7 May 2021 Accepted: 28 November 2021

Published online: 04 December 2021

\section{References}

1. Straub V, Murphy A, Udd B, Corrado A, Aymé S, Bönneman C, et al. 229th ENMC international workshop: limb girdle muscular dystrophies - nomenclature and reformed classification Naarden, the Netherlands, 17-19 March 2017. Neuromuscul Disord. 2018;28:702-10. https://doi.org/ 10.1016/j.nmd.2018.05.007.

2. Nascimbeni AC, Fanin M, Tasca E, Angelini C. Transcriptional and translational effects of intronic CAPN3 gene mutations. Hum Mutat. 2010:31:E1658-69. https://doi.org/10.1002/humu.21320.

3. Sorimachi $\mathrm{H}$, Hata S, Ono Y. Expanding members and roles of the calpain superfamily and their genetically modified animals. Exp Anim. 2010;59:549-66. https://doi.org/10.1538/expanim.59.549.

4. Martinez-Thompson JM, Moore SA, LiewluckT. A novel CAPN3 mutation in late-onset limb-girdle muscular dystrophy with early respiratory insufficiency. J Clin Neurosci. 2018;53:229-31. https://doi.org/10.1016/j.jocn. 2018.04.025.

5. Blázquez L, Azpitarte M, Sáenz A, Goicoechea M, Otaegui D, Ferrer X, et al. Characterization of novel CAPN3 isoforms in white blood cells: an alternative approach for limb-girdle muscular dystrophy $2 \mathrm{~A}$ diagnosis. Neurogenetics. 2008;9:173-82.

6. Fanin M, Nardetto L, Nascimbeni AC, Tasca E, Spinazzi M, Padoan R, et al Correlations between clinical severity, genotype and muscle pathology in limb girdle muscular dystrophy type 2A. J Med Genet. 2007:44:609-14. https://doi.org/10.1136/jmg.2007.050328.

7. Stenson PD, Ball EV, Mort M, Phillips AD, Shiel JA, Thomas NST, et al. Human gene mutation database $\left(\mathrm{HGMD}^{\circledR}{ }^{\circledR}\right): 2003$ update. Hum Mutat. 2003;21:577-81. https://doi.org/10.1002/humu.10212.

8. Fokkema IFAC, Taschner PEM, Schaafsma GCP, Celli J, Laros JFJ, den Dunnen JT. LOVD v.2.0: the next generation in gene variant databases. Hum Mutat. 2011;32:557-63. https://doi.org/10.1002/humu.21438.

9. Caminsky NG, Mucaki EJ, Rogan PK. Interpretation of mRNA splicing mutations in genetic disease: review of the literature and guidelines for information-theoretical analysis. F1000Research. 2015;3:282. https://doi. org/10.12688/f1000research.5654.2.

10. Narayanaswami P, Weiss M, Selcen D, David W, Raynor E, Carter G, et al. Evidence-based guideline summary: diagnosis and treatment of limb-girdle and distal dystrophies: report of the guideline development subcommittee of the American Academy of Neurology and the practice issues review panel of the American Association of Neur. Neurology. 2014:83:1453-63. https://doi.org/10.1212/WNL.0000000000000892.
11. Javadi A, Shamaei M, Ziazi LM, Pourabdollah M, Dorudinia A, Seyedmehdi SM, et al. Qualification study of two genomic DNA extraction methods in different clinical samples. Tanaffos. 2014;13:41-7.

12. Wang K, Li M, Hakonarson H. ANNOVAR: functional annotation of genetic variants from high-throughput sequencing data. Nucleic Acids Res. 2010;38:e164-4. https://doi.org/10.1093/nar/gkq603.

13. Häffner K, Speer A, Hübner C, Voit T, Oexle K. A small in-frame deletion within the protease domain of muscle-specific calpain, p94 causes earlyonset limb-girdle muscular dystrophy 2A. Hum Mutat. 1998;11:S298-300. https://doi.org/10.1002/humu.1380110193.

14. Stehlíková K, Skálová D, Zídková J, Mrázová L, Vondráček P, Mazanec $\mathrm{R}$, et al. Autosomal recessive limb-girdle muscular dystrophies in the Czech Republic. BMC Neurol. 2014;14:154. https://doi.org/10.1186/ s12883-014-0154-7.

15. Fanin M, Nascimbeni AC, Tasca E, Angelini C. How to tackle the diagnosis of limb-girdle muscular dystrophy 2A. Eur J Hum Genet. 2009;17:598-603. https://doi.org/10.1038/ejhg.2008.193.

16. Piluso G. Extensive scanning of the calpain-3 gene broadens the spectrum of LGMD2A phenotypes. J Med Genet. 2005;42:686-93. https://doi. org/10.1136/jmg.2004.028738.

17. Landrum MJ, Lee JM, Riley GR, Jang W, Rubinstein WS, Church DM, et al. ClinVar: public archive of relationships among sequence variation and human phenotype. Nucleic Acids Res. 2014;42:D980-5. https://doi.org/ 10.1093/nar/gkt1113.

18. Lin H, Hargreaves KA, Li R, Reiter JL, Wang Y, Mort M, et al. RegSNPs-intron: a computational framework for predicting pathogenic impact of intronic single nucleotide variants. Genome Biol. 2019;20:254. https://doi.org/10. 1186/s13059-019-1847-4

19. Richards S, Aziz N, Bale S, Bick D, Das S, Gastier-Foster J, et al. Standards and guidelines for the interpretation of sequence variants: a joint consensus recommendation of the American College of Medical Genetics and Genomics and the Association for Molecular Pathology. Genet Med. 2015;17:405-23. https://doi.org/10.1038/gim.2015.30.

20. Untergasser A, Cutcutache I, Koressaar T, Ye J, Faircloth BC, Remm M, et al. Primer3-new capabilities and interfaces. Nucleic Acids Res. 2012;40:e115-5. https://doi.org/10.1093/nar/gks596.

21. Ye J, Coulouris G, Zaretskaya I, Cutcutache I, Rozen S, Madden TL. PrimerBLAST: a tool to design target-specific primers for polymerase chain reaction. BMC Bioinformatics. 2012;13:134. https://doi.org/10.1186/ 1471-2105-13-134.

22. Altshuler DL, Durbin RM, Abecasis GR, Bentley DR, Chakravarti A, Clark AG, et al. A map of human genome variation from population-scale sequencing. Nature. 2010;467:1061-73. https://doi.org/10.1038/nature09534.

23. Sherry ST. dbSNP: the NCBI database of genetic variation. Nucleic Acids Res. 2001;29:308-11. https://doi.org/10.1093/nar/29.1.308.

24. Hamosh A, Scott AF, Amberger JS, Bocchini CA, McKusick VA. Online Mendelian Inheritance in Man (OMIM), a knowledgebase of human genes and genetic disorders. Nucleic Acids Res. 2005;33 DATABASE ISS.:D514-7. https://doi.org/10.1093/nar/gki033.

25. Rath A, Olry A, Dhombres F, Brandt MM, Urbero B, Ayme S. Representation of rare diseases in health information systems: the orphanet approach to serve a wide range of end users. Hum Mutat. 2012;33:803-8. https://doi. org/10.1002/humu.22078.

26. Hubbard T, Barker D, Birney E, Cameron G, Chen Y, Clark L, et al. The Ensembl genome database project. Nucleic Acids Res. 2002;30:38-41. https://doi.org/10.1093/nar/30.1.38.

27. Karczewski KJ, Francioli LC, Tiao G, Cummings BB, Alföldi J, Wang Q, et al. The mutational constraint spectrum quantified from variation in 141,456 humans. Nature. 2020;581:434-43. https://doi.org/10.1038/ s41586-020-2308-7.

28. Schwarz JM, Cooper DN, Schuelke M, Seelow D. MutationTaster2: mutation prediction for the deep-sequencing age. Nat Methods. 2014:11:3612. https://doi.org/10.1038/nmeth.2890.

29. Desmet F-O, Hamroun D, Lalande M, Collod-Béroud G, Claustres M, Béroud C. Human splicing finder: an online bioinformatics tool to predict splicing signals. Nucleic Acids Res. 2009;37:e67-7. https://doi.org/10. 1093/nar/gkp215.

30. Zhang X, Li M, Lin H, Rao X, Feng W, Yang Y, et al. regSNPs-splicing: a tool for prioritizing synonymous single-nucleotide substitution. Hum Genet. 2017:136:1279-89. https://doi.org/10.1007/s00439-017-1783-x. 
31. Sievers F, Wilm A, Dineen D, Gibson TJ, Karplus K, Li W, et al. Fast, scalable generation of high-quality protein multiple sequence alignments using Clustal omega. Mol Syst Biol. 2011;7:539. https://doi.org/10.1038/msb. 2011.75.

32. Bateman A. UniProt: a worldwide hub of protein knowledge. Nucleic Acids Res. 2019;47:D506-15. https://doi.org/10.1093/nar/gky1049.

33. Finn RD, Bateman A, Clements J, Coggill P, Eberhardt RY, Eddy SR, et al Pfam: the protein families database. Nucleic Acids Res. 2014;42:D222-30. https://doi.org/10.1093/nar/gkt1223.

34. Krawczak M, Reiss J, Cooper D. The mutational spectrum of single basepair substitutions in mRNA splice junctions of human genes: causes and consequences. Hum Genet. 1992;90:41-54. https://doi.org/10.1007/ BF00210743.

35. Krawczak M, Thomas NST, Hundrieser B, Mort M, Wittig M, Hampe J, et al. Single base-pair substitutions in exon-intron junctions of human genes: nature, distribution, and consequences for mRNA splicing. Hum Mutat. 2007;28:150-8. https://doi.org/10.1002/humu.20400.

36. Wang G-S, Cooper TA. Splicing in disease: disruption of the splicing code and the decoding machinery. Nat Rev Genet. 2007;8:749-61. https://doi. org/10.1038/nrg2164

37. Stehlíková K, Zapletalová E, Sedláčková J, Hermanová M, Vondráček P, Mař́ková T, et al. Quantitative analysis of CAPN3 transcripts in LGMD2A patients: involvement of nonsense-mediated mRNA decay. Neuromuscul Disord. 2007;17:143-7. https://doi.org/10.1016/j.nmd.2006.10.001.

38. Krahn M, Pécheux C, Chapon F, Béroud C, Drouin-Garraud V, Laforet $P$, et al. Transcriptional explorations of CAPN3 identify novel splicing mutations, a large-sized genomic deletion and evidence for messenger RNA decay. Clin Genet. 2007;72:582-92. https://doi.org/10.1111/j.1399-0004. 2007.00906.x

39. Reddy HM, Cho K-A, Lek M, Estrella E, Valkanas E, Jones MD, et al. The sensitivity of exome sequencing in identifying pathogenic mutations for LGMD in the United States. J Hum Genet. 2017;62:243-52. https://doi. org/10.1038/jhg.2016.116.

40. Macias A, Fichna JP, Topolewska M, Redowicz M, Kaminska AM, KosteraPruszczyk A. Targeted next-generation sequencing reveals mutations in non-coding regions and potential regulatory sequences of Calpain-3 gene in polish limb-girdle muscular dystrophy patients. Front Neurosci. 2021;15:1-16.

41. Vandenbroucke I, Callens T, De Paepe A, Messiaen L. Complex splicing generates great diversity in human NFI transcripts. BMC Genomics. 2002;3:13. https://doi.org/10.1186/1471-2164-3-13.
42. Zhu J, Chen G, Zhu S, Li S, Wen Z, Bin Li, et al. Identification of Tissue-Specific Protein-Coding and Noncoding Transcripts across 14 Human Tissues Using RNA-seq. Sci Rep. 2016;6:28400. https://doi.org/10.1038/srep28400.

43. Hug N, Longman D, Cáceres JF. Mechanism and regulation of the nonsense-mediated decay pathway. Nucleic Acids Res. 2016;44:1483-95. https://doi.org/10.1093/nar/gkw010.

44. Raimondeau E, Bufton JC, Schaffitzel C. New insights into the interplay between the translation machinery and nonsense-mediated mRNA decay factors. Biochem Soc Trans. 2018;46:503-12. https://doi.org/10. 1042/BST20170427.

45. Fusco C, Morlino S, Micale L, Ferraris A, Grammatico P, Castori M. Characterization of Two Novel Intronic Variants Affecting Splicing in FBN1Related Disorders. Genes (Basel). 2019;10:442. https://doi.org/10.3390/ genes10060442.

46. Lonsdale J, Thomas J, Salvatore M, Phillips R, Lo E, Shad S, et al. The genotype-tissue expression (GTEx) project. Nat Genet. 2013;45:580-5 https://doi.org/10.1038/ng.2653.

47. Ono Y, Ojima K, Shinkai-Ouchi F, Hata S, Sorimachi H. An eccentric calpain CAPN3/p94/calpain-3. Biochimie. 2016;122:169-87. https://doi.org/10. 1016/j.biochi.2015.09.010.

48. Lasa-Elgarresta J, Mosqueira-Martín L, Naldaiz-Gastesi N, Sáenz A, López de Munain A, Vallejo-Illarramendi A. Calcium mechanisms in limb-girdle muscular dystrophy with CAPN3 mutations. Int J Mol Sci 2019;20:4548. https://doi.org/10.3390/ijms20184548.

49. Ojima K, Ono Y, Hata S, Noguchi S, Nishino I, Sorimachi H. Muscle-specific calpain-3 is phosphorylated in its unique insertion region for enrichment in a myofibril fraction. Genes Cells. 2014;19:830-41. https://doi.org/10. $1111 /$ gtc. 12181.

50. Ye Q, Campbell RL, Davies PL. Structures of human calpain-3 protease core with and without bound inhibitor reveal mechanisms of calpain activation. J Biol Chem. 2018;293:4056-70. https://doi.org/10.1074/jbc. RA117.001097.

\section{Publisher's Note}

Springer Nature remains neutral with regard to jurisdictional claims in published maps and institutional affiliations.
Ready to submit your research? Choose BMC and benefit from:

- fast, convenient online submission

- thorough peer review by experienced researchers in your field

- rapid publication on acceptance

- support for research data, including large and complex data types

- gold Open Access which fosters wider collaboration and increased citations

- maximum visibility for your research: over $100 \mathrm{M}$ website views per year

At BMC, research is always in progress.

Learn more biomedcentral.com/submissions 